\title{
Advanced ankylosing spondylitis: a multisite, multimodality densitometric analysis for investigation of bone loss in the axial and appendicular skeleton
}

\author{
Stavroula Theodorou' ${ }^{1}$ (D), Daphne Theodorou ${ }^{2 *}$ (1), \\ Yousuke Kakitsubata ${ }^{3}$ (D) loannis Gelalis ${ }^{4}$ (D) Niki Tsifetaki $^{5}$
}

\section{SUMMARY}

OBJECTIVE: The aim of this study was to investigate if there is a bias in bone mineral density measurements among major densitometric techniques across multiple skeletal sites.

METHODS: In 25 advanced ankylosing spondylitis patients, bone mineral density measurements were acquired in the lumbar spine, the hip, and the forearm.

RESULTS: In total, $60 \%$ of patients had a bone mineral density Z-score of -2 or less at one or more skeletal sites. Dedicated loss of cortical bone was identified at the distal forearm (60\% of patients). Differences in bone mineral density measurements across all densitometric techniques were highly significant $(p \leq 0.001)$. Bone loss was more striking in spinal trabecular bone by three-dimensional quantitative computed tomography [Z-score -2.1] versus dual-energy X-ray absorptiometry [Z-score 0]. A trabecular bone loss quantified by quantitative computed tomography was about twice as much as a cortical bone loss by single-energy $X$-ray absorptiometry $(p=0.001)$.

CONCLUSIONS: Low bone mineral density is prevalent in advanced ankylosing spondylitis patients, predominating in the spine. Bone mineral density measurements have systematic differences when compared to each other. Knowledge of these offsets is useful for improved diagnosis of regional bone loss that allows for targeted treatment of osteoporosis. Three-dimensional quantitative computed tomography is more suitable for evaluating spinal osteoporosis in advanced ankylosing spondylitis than dual-energy $\mathrm{X}$-ray absorptiometry, which rather underestimates bone loss. KEYWORDS: Ankylosing spondylitis. Bone mineral density. Osteoporosis. CT X ray. Dual-energy X-ray absorptiometry.

\section{INTRODUCTION}

Ankylosing spondylitis (AS) is characterized by spinal ligamentous calcification, osteoporosis, and increased risk for fractures $^{1-3}$. Reportedly, osteoporosis occurs with an incidence ranging between 18.7 and $62 \%{ }^{4}$, and diagnosis becomes important for targeted pharmacologic therapies 5 .

Dual-energy X-ray absorptiometry (DXA) is the bone densitometric technique of choice for evaluating bone mineral density (BMD) in AS patients ${ }^{6-11}$. To acquire accurate BMD measurements, we used three-dimensional quantitative computed tomography (3DQCT) supplanted by DXA and single-energy X-ray absorptiometry (SXA), as well as compared 3DQCT with the other bone densitometric methods. We investigated if there is a bias in BMD measurements across all densitometric techniques when compared to each other.

\footnotetext{
'University Hospital of Ioannina, Department of Radiology - loannina, Greece.

${ }^{2}$ General Hospital of Ioannina G. Hatzikosta, Department of Radiology - Ioannina, Greece.

${ }^{3}$ Miyazaki Konan Hospital, Department of Radiology and Bone Metabolism - Miyazaki, Japan.

${ }^{4}$ University Hospital of Ioannina, Department of Orthopaedic Surgery - Ioannina, Greece.

${ }^{5}$ General Hospital of Ioannina, Rheumatology Clinic, Department of Internal Medicine - Ioannina, Greece.

*Corresponding author: daphne_theodorou@hotmail.com

Conflicts of interest: the authors declare there are no conflicts of interest. Funding: none.

Received on July 19, 2021. Accepted on August 18, 2021.
} 


\section{METHODS}

\section{Patients and spine radiographic assessment}

We included 25 patients ( 20 males, 5 females; $32-80$ years) with chronic $\mathrm{AS}^{12}$ in our study. Prevalent fractures were defined using the grading scheme for vertebral deformity described by Genant ${ }^{13}$.

\section{Bone density measurements}

DXA-DXA measurements of bone mass were acquired in the L-spine (L1-L4) and the proximal femur. DXA provides an estimate of integral BMD representing both cortical and trabecular bone ${ }^{14}$.

$S X A-\mathrm{BMD}$ was measured in the non-dominant forearm, i.e., distal and ultradistal sites, by SXA. The distal forearm measurement is predominantly of cortical (87\%) bone, and the ultradistal forearm is of trabecular $(65 \%)$ bone $^{14}$.

$3 D Q C T-A$ total of $22(88 \%)$ patients underwent BMD measurements in the L-spine (L2-L3) by QCT (i.e., 3DQCT) supplanted with three-dimensional Pro-software (Mindways, San Francisco, CA, USA). QCT allows a selective assessment of cortical and trabecular bone density and a true volumetric assessment of bone mass. BMD was judged reduced if the Z-score was equal to or below $-2^{15}$.

\section{Statistical analyses}

The Wilcoxon signed-rank test was used to assess the differences between BMD Z-scores across skeletal sites. To test for differences by fracture status, the Mann-Whitney $U$ test was used for median BMD Z-scores at each skeletal site. Correlations between BMD measurements were expressed as Spearman's correlation coefficients. A reduced probability level of 0.002 was accepted as significant in all analyses, except for the twotailed Spearman's correlation $(\mathrm{p}=0.01)$.

\section{RESULTS}

\section{Patient characteristics}

The patient demographic variables are summarized in Table 1.

Fractures: The overall fracture rate was $56 \%$ (14/25 patients). The development of fracture was similar between men and women in terms of age and body mass index (BMI). The L-spine was the most common site of fracture $(36 \%$; $9 / 25)$.

\section{Bone mineral density measurements}

Table 1 presents cumulative BMD Z-score measures for our study population. The median $Z$-scores at all eight sites measured were predominantly negative, indicating an overall trend toward a significant reduction of the BMD in patients (Figure
1). A BMD Z-score of -2 or less at one or more skeletal sites (osteoporosis) was found in 15 of the 25 AS patients (60\%). A further 19 patients (76\%) had a Z-score between -1 and -2 at any site (osteopenia). With DXA, spinal BMD [Z-score, $0(-5.2-3.4)]$ was decreased in eight patients (32\%). Using 3DQCT, spinal trabecular bone loss [Z-score, -2.1 (-5.2 -0.05)] was identified in 19 patients $(86.3 \%)$.

Total hip measurements showed decreased BMD in 10 patients (52.6\%). BMD was reduced at the femoral neck in 10 patients $(43.4 \%)$, and trochanteric BMD was reduced in nine patients $(39.1 \%)$. Measurements at the distal forearm (cortical bone) and ultradistal forearm yielded reduced BMD [Z-score, -1.1 (-4.2-0.8)] in 12 patients (60\%) and [Z-score, $-0.8(-4.5-1.1)]$ in eight patients (40\%), respectively. Trabecular bone loss (by QCT) was about twice as much as cortical bone loss (by SXA) ( $\mathrm{p}=0.001)$. Despite statistically not significant differences in BMD between fractured and non-fractured patients $(\mathrm{p}<0.002)$, the analysis of $\mathrm{Z}$-scores showed a trend toward bone loss across all sites, with the exception of the forearm (Figure 2).

Table 1. Median (range) demographic and bone mineral density Z-scores of patients with advanced Ankylosing spondylitis.

\begin{tabular}{|c|c|}
\hline & $\begin{array}{l}\text { Ankylosing spondylitis } \\
\text { patients }(n=25)\end{array}$ \\
\hline Age (years) & $55(32-80)$ \\
\hline Weight (kg) & $68.1(49-113)$ \\
\hline Height (m) & $1.64(1.4-1.82)$ \\
\hline Body mass index $\left(\mathrm{kg} / \mathrm{m}^{2}\right)$ & $24.5(18.3-35.5)$ \\
\hline Z-Distal forearm & $\begin{array}{c}-1.1(-4.2-0.8) \\
n=20\end{array}$ \\
\hline Z-Ultra distal forearm & $\begin{array}{c}-0.8(-4.5-1.1) \\
n=20\end{array}$ \\
\hline $\begin{array}{l}\text { Z-Lumbar spine Dual-energy } \\
\text { X-ray absorptiometry }\end{array}$ & $\begin{array}{c}0(-5.2-3.4) \\
n=25\end{array}$ \\
\hline $\begin{array}{l}\text { Z-Lumbar spine quantitative } \\
\text { computed tomography }\end{array}$ & $\begin{array}{c}-2.1(-5.2--0.05) \\
n=22\end{array}$ \\
\hline Z-Femoral neck & $\begin{array}{c}-0.9(-3.3-1.8) \\
n=23\end{array}$ \\
\hline Z-Total hip & $\begin{array}{c}-1(-3.3-1.8) \\
n=19\end{array}$ \\
\hline Z-Trochanter & $\begin{array}{c}-0.8(-2.9-1.6) \\
n=23\end{array}$ \\
\hline Z-Ward's triangle & $\begin{array}{c}-0.8(-3.6-0.9) \\
n=23\end{array}$ \\
\hline
\end{tabular}




\section{Relationships between BMD}

Z-scores assessed at multiple sites by various bone densitometric methods

Correlations between the different bone density metrics were analyzed. In comparing the decrease in BMD at the L-spine as measured by DXA and 3DQCT, there was a significant difference between densitometric techniques $(\mathrm{p}<0.001)$. We found a moderate, yet significant, correlation between the 3DQCT L-spine BMD measurements and femoral neck DXA-acquired BMD measurements (Spearman's correlation coefficient $r=0.699, p=0.001$ ). Significant differences were also found when comparing QCT L-spine measurements of BMD versus SXA-based BMD measurements at the distal and ultradistal forearm $(\mathrm{p}=0.001)$. Similar significant differences in BMD Z-scores were recorded between L-spine measurements by QCT and DXA-based measurements at the femoral neck $(\mathrm{p}<0.001)$, Ward's triangle $(\mathrm{p}<0.001)$, and the trochanter $(\mathrm{p}<0.001)$.

Measurements proved poor correlation between Z-scores by $3 \mathrm{DQCT}$ at the $\mathrm{L}$-spine and $\mathrm{Z}$-scores by $\mathrm{DXA}$ at the $\mathrm{L}$-spine $(r=0.447, p=0.037)$, the trochanter $(r=0.544, p=0.013)$, total hip $(r=0.6, p=0.011)$, and the forearm (by SXA) ( $r=0.365-0.5$, $\mathrm{p}=0.041-0.15)$. No correlation was found between Z-scores either at the L-spine by DXA or at the distal forearm by SXA $(\mathrm{r}=0.368, \mathrm{p}=0.11)$.
DXA-acquired hip measurements showed that there was a strong correlation between $\mathrm{Z}$-scores at the trochanter and the femoral neck, total hip, and ultradistal forearm $(\mathrm{r}=0.793$ $0.887, \mathrm{p}=0$ ). A similar strong correlation was noted between

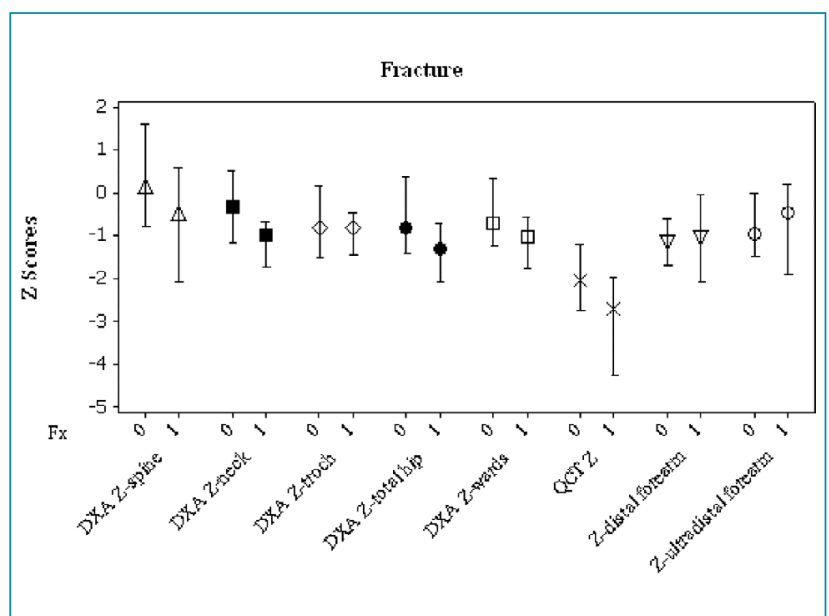

Figure 2. Spinal (Dual-energy X-ray absorptiometry and quantitative computed tomography), femoral neck (Dualenergy X-ray absorptiometry), trochanteric (Dual-energy X-ray absorptiometry), total hip (Dual-energy X-ray absorptiometry), and forearm (single-energy $\mathrm{X}$-ray absorptiometry) Z-scores (median values) for Ankylosing spondylitis patients with (1) and without (0) fractures.

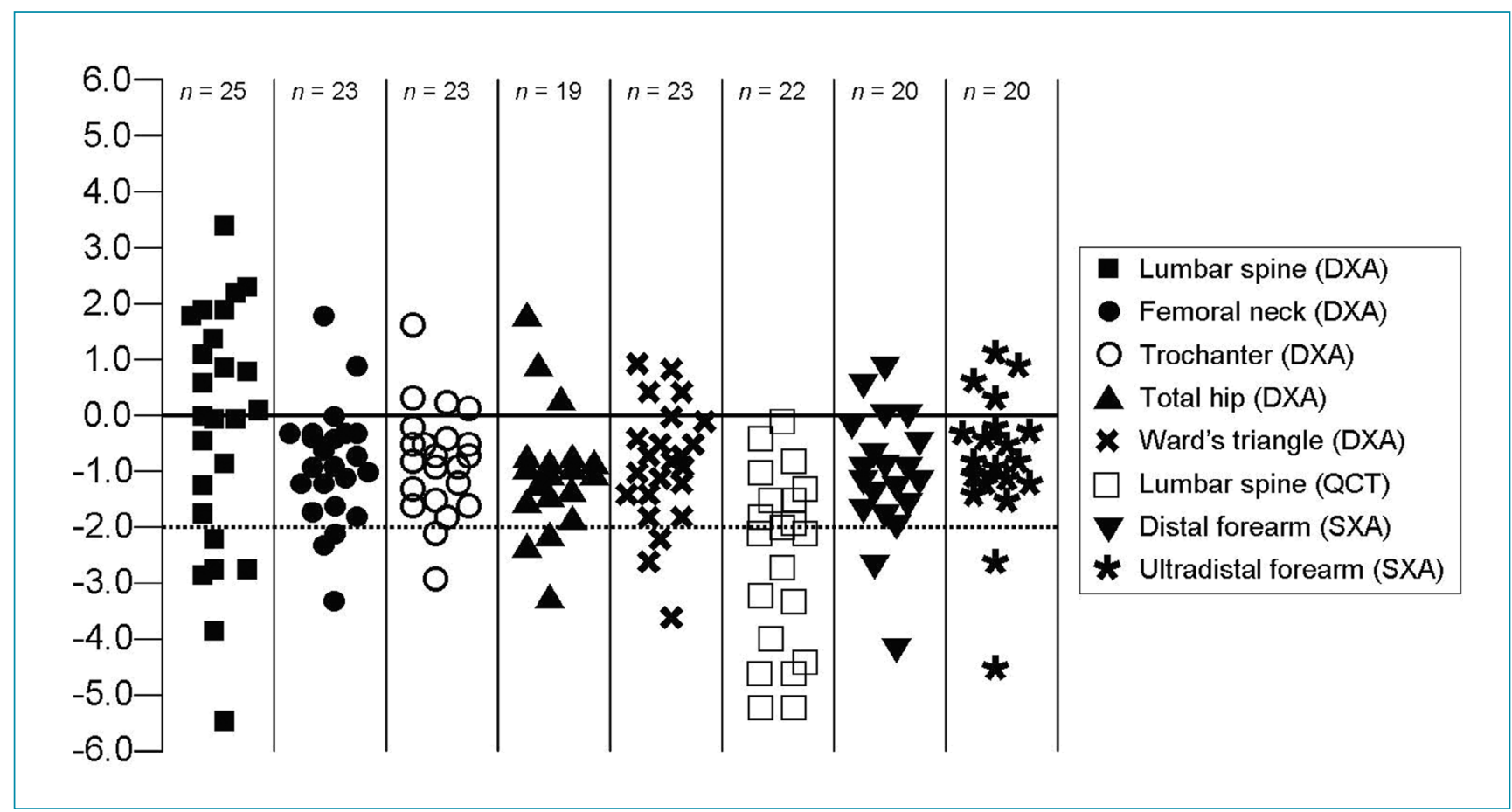

Figure 1. Bone mineral density Z-scores in ankylosing spondylitis patients. The solid horizontal line indicates the mean Bone mineral density Z-score of an age- and sex-matched control population, and the broken horizontal line indicates a Bone mineral density Z-score of -2 . 
Z-score at the femoral neck and the total hip $(\mathrm{r}=0.794, \mathrm{p}=0)$. Correlation between $\mathrm{Z}$-scores (by DXA) at the $\mathrm{L}$-spine and the femoral neck $(r=0.683, p=0)$, trochanter $(r=0.723, p=0)$, and total hip $(\mathrm{r}=0.701, \mathrm{p}=0.001)$ was good.

Distal forearm Z-scores (calculated by SXA measurements) were correlated well with the trochanter $(r=0.766, p=0)$, the femoral neck $(\mathrm{r}=0.744, \mathrm{p}=0)$, and the total hip $(\mathrm{r}=0.695, \mathrm{p}=0.003)$. Similarly, the ultradistal forearm measurements (by SXA) were correlated well with the distal forearm $(r=0.764, p=0)$, the femoral neck $(r=0.754, p=0)$, the $\mathrm{L}$-spine $(r=0.651, \mathrm{p}=0.002)$, and the total hip $(r=0.683, p=0.004)$. Comparing $Z$-scores across different sites, with the exclusion of those obtained by QCT, the differences no longer reached the statistical significance (p-values from 0.002-0.983).

\section{DISCUSSION}

The characteristics of the AS patients are similar to those in other studies with respect to sex, age, BMI, and fractures ${ }^{16,17}$. Few studies have used dedicated QCT measurements to determine the bone mass in AS, which may have implications for treatment ${ }^{18}$. The major findings in this study indicate that 3DQCT can be effectively used to acquire bone mass measurements that differ significantly from measurements acquired by other bone densitometric methods, in both the trabecular and cortical bone. No prior studies have used QCT in addition to DXA and SXA to evaluate osteoporosis in patients with advanced AS.

In the pathophysiology of bone loss in AS, proposed mechanisms ${ }^{1,18,19}$ have included subclinical inflammatory bowel disease with malabsorption of calcium and vitamin $\mathrm{D}^{18,20,21}$ and secondary hyperparathyroidism, which may induce intracortical bone loss. Once there, the appendicular skeleton (rich in cortical bone) is more likely to be offended by changes in parathyroid hormone due to the malabsorption of calcium. Our finding of bone loss in the distal forearm of patients, an area rich in cortical bone ${ }^{14}$, lends further support to the coexistence of secondary hyperparathyroidism and AS.

Most previous investigators have focused on bone mass changes at the L-spine and proximal femur and have not reported the changes of bone mass occurring in the appendicular skeleton ${ }^{21,22}$. Sarikaya et al. ${ }^{19}$ concluded that osteoporosis affects the hip sparing the forearm. Unlike these investigators, Will et al. ${ }^{23}$ found a $5 \%$ decrease in BMD at the carpus, suggesting that bone loss involves both the cortical and trabecular bone. In accordance with Will et al. ${ }^{23}$, we found reduced bone density at the radius, as opposed to the previous studies $^{2,10,19,24}$. Other studies also support our results about reduced cortical BMD at peripheral sites ${ }^{2,8}$, suggesting a possible link between systemic inflammation and bone resorption. Our measurements show that the trabecular and cortical bone appear to have considerable differences in the rate of bone loss, with the overall difference of trabecular versus cortical bone loss be nearly double $(\mathrm{p}=0.001)$. Similar findings are reported by other investigators ${ }^{17}$ who postulate that trabecular and cortical bone compartments appear to have different biological behaviors to systemic inflammation.

In AS, the frequency of osteoporotic fractures varies from 0 to $40.9 \% 3,3,6,11,16,20,22$. Our data indicate a high vertebral fracture rate of $36 \%$, owing probably to advanced AS. Although the decreased bone mass was not statistically significant between fractured and non-fractured patients, in our series, bone loss was trending across all sites with the exception of the forearm. A possible explanation for this noteworthy finding would relate to the non-weight-bearing properties of the forearm as opposed to other sites. Similarly, other investigators ${ }^{25}$ have reported no significant BMD differences at the L-spine between fractured and non-fractured patients, whereas BMD at the femoral neck ${ }^{5}$ and total hip was significantly lower in fractured patients.

The frequency of bone loss in AS varies, depending on the site used for the measurement of the BMD. A significant decrease in $\mathrm{BMD}$ of the proximal femur has been documented in late $\mathrm{AS}^{8,25}$. Karberg et al. ${ }^{10}$ detected a bone loss in $86 \%$ of the AS patients at the femoral neck. Bone loss was found in $54.5 \%$ of patients at the femoral neck and in $52.3 \%$ of patients at the trochanter and total hip, with an overall bone loss recorded in $69 \%$ of the patients ${ }^{7}$. Other investigators ${ }^{9,11}$ have reported variably decreased BMD at the femoral neck and L-spine in $13.7-41.2 \%$ and $18.7-$ $46.5 \%$ of AS patients, respectively. We found bone loss in $39.1 \%$ of patients either at the femoral neck or at the trochanter, $52.6 \%$ at the total hip, and $32 \%$ at the spine by DXA.

As DXA and SXA are the projectional 2D techniques, the discrimination between the cortical and trabecular bone is not feasible. QCT is unique among current bone densitometric techniques, providing separate estimates of trabecular and cortical BMD as a true volumetric mineral density. Indeed, this exquisite capability to distinguish BMD measurements between bone compartments is important because the trabecular bone has a higher turnover rate than cortical bone and greater responsiveness to many metabolic stimuli and drugs. QCT confers the benefit of excluding confounding factors that may falsely elevate BMD such as extraneous calcification, in contrast to DXA or SXA. In patients with late-stage AS, Lee et al. ${ }^{8}$ found decreased BMD at the L-spine when measured by QCT (Z-score $-3.85 \pm 1.33$ ), whereas BMD at the same site was not low when measured by DXA (Z-score $0.79 \pm 2.57)$. Similarly, another study ${ }^{10}$ has indicated that bone loss in the spine measured by QCT (54\% of patients) is not equivalent to bone loss measured by DXA ( $40 \%$ of patients). 
Additional studies in AS patients have validated discrepancies between QCT and DXA measurements of BMD ${ }^{24}$. Our results determine low bone mass by QCT in $86 \%$ of AS patients, as opposed to $32 \%$ of the patients by DXA, and are supported by the available literature.

Limitations to this study include an inherent selection bias created because only patients with advanced disease were studied without comparison to a reference standard. Also, a relatively small number of patients with late-stage AS were examined with the various bone densitometric techniques. Finally, not all densitometric techniques were applied in all patients. Notwithstanding its limitations, however, this study suggests that in late AS patients, discrepancies in BMD values are present among all densitometric techniques when compared to each other.

Our measurements indicate that generalized reductions in BMD are present not only at the sites of predominant trabecular bone (spine), or predominant cortical bone (distal forearm), but also at the sites of mixed cortical and trabecular bone (proximal femur), implying that both the trabecular and cortical bone components, in both the axial and appendicular skeletal sites, are offended in advanced AS. Although DXA remains the most widely accepted clinical tool for the measurement of the
BMD, our findings suggest that QCT may play a unique and pivotal role in the accurate assessment of spinal osteoporosis associated with advanced AS. Most importantly, our results show that the true pattern of the demineralization of the axial skeleton may be more accurately and precisely reflected by QCT. It appears that confounding factors related to the state of the AS disease can contribute to spurious results by DXA. Based on our results, we clearly recommend the use of QCT over DXA that will allow clinicians the optimal assessment of the true spinal BMD, in late-stage AS.

\section{ACKNOWLEDGEMENT}

The authors wish to thank Rebecca L. Ashby for her help with statistical analysis of the data.

\section{AUTHORS CONTRIBUTIONS}

DJT: Conceptualization, Writing - original draft, Writing review \& editing. SJT: Data curation, Formal analysis, Writing - review \& editing. YK: Conceptualization, Writing - review \& editing. ID: Data curation, Formal analysis. NT: Data curation, Formal analysis.

\section{REFERENCES}

1. Resnick D, Niwayama G. Ankylosing spondylitis. In: Resnick $\mathrm{D}$ (editor). Diagnosis of bone and joint Disorders. 3rd ed. Philadelphia: WB Saunders;1995. p.1008-74

2. Klingberg E, Lorentzon M, Göthlin J, Mellström D, Geijer M, Ohlsson C, et al. Bone microarchitecture in ankylosing spondylitis and the association with bone mineral density, fractures, and syndesmophytes. Arthritis Res Ther. 2013;15(6):R179. https:// doi.org/10.1186/ar4368

3. Feldtkeller E, Vosse D, Geusens P, van der Linden S. Prevalence and annual incidence of vertebral fractures in patients with ankylosing spondylitis. Rheumatol Int. 2006;26(3):234-9. https://doi.org/10.1007/s00296-004-0556-8

4. Bessant $R$, Keat $A$. How should clinicians manage osteoporosis in ankylosing spondylitis? J Rheumatol. 2002;29(7):1511-9. PMID: 12136913

5. Geusens P, De Winter L, Quaden D, Vanhoof J, Vosse D, van den Bergh J, et al. The prevalence of vertebral fractures in spondyloarthritis: relation to disease characteristics, bone mineral density, syndesmophytes and history of back pain and trauma. Arthritis Res Ther. 2015;17:294. https://doi. org/10.1186/s13075-015-0809-9

6. Jun JB, Joo KB, Her MY, Kim TH, Bae SC, Yoo DH, et al. Femoral bone mineral density is associated with vertebral fractures in patients with ankylosing spondylitis: a crosssectional study. J Rheumatol. 2006;33(8):1637-41. PMID: 16881119

7. Aydin T, Karacan I, Demir SE, Sahin Z. Bone loss in males with ankylosing spondylitis: its relation to sex hormone levels. Clin Endocrinol (Oxf). 2005;63(4):467-9. https://doi. org/10.1111/j.1365-2265.2005.02369.x

8. Lee YS, Schlotzhauer T, Ott SM, van Vollenhoven RF, Hunter J, Shapiro J, et al. Skeletal status of men with early and late ankylosing spondylitis. Am J Med. 1997;103(3):233-41. https:// doi.org/10.1016/s0002-9343(97)00143-5

9. El Maghraoui A, Borderie D, Cherruau B, Edouard R, Dougados $\mathrm{M}$, Roux C. Osteoporosis, body composition, and bone turnover in ankylosing spondylitis. J Rheumatol. 1999;26(10):2205-9. PMID: 10529141

10. Karberg K, Zochling J, Sieper J, Felsenberg D, Braun J. Bone loss is detected more frequently in patients with ankylosing spondylitis with syndesmophytes. J Rheumatol. 2005;32(7):1290-8. PMID: 15996067

11. Toussirot E, Michel F, Wendling D. Bone density, ultrasound measurements and body composition in early ankylosing spondylitis. Rheumatology (Oxford). 2001;40(8):882-8. https:// doi.org/10.1093/rheumatology/40.8.882

12. van der Linden S, Valkenburg HA, Cats A. Evaluation of diagnostic criteria for ankylosing spondylitis. A proposal for modification of the New York criteria. Arthritis Rheum. 1984;27(4):361-8. https://doi.org/10.1002/art.1780270401

13. Genant HK, Wu CY, van Kuijk C, Nevitt MC. Vertebra fracture assessment using a semiquantitative technique. J Bone Miner Res. 1993;8(9):1137-48. https://doi.org/10.1002/ jbmr.5650080915 
14. Haworth CS, Selby PL, Webb AK, Dodd ME, Musson H, McL Niven $\mathrm{R}$, et al. Low bone mineral density in adults with cystic fibrosis. Thorax. 1999;54(11):961-7. https://doi.org/10.1136/thx.54.11.961

15. Lewiecki E, Gordon C, Baim S, Leonard MB, Bishop NJ, Bianchi ML, et al. International Society for Clinical Densitometry 2007 adult and pediatric official positions. Bone. 2008;43(6):111521. https://doi.org/10.1016/j.bone.2008.08.106

16. Klingberg $E$, Lorentzon M, Mellström D, Geijer M, Göthlin J, Hilme E, et al. Osteoporosis in ankylosing spondylitis prevalence, risk factors and methods of assessment. Arthritis Res Ther. 2012;14(3):R108. https://doi.org/10.1186/ar3833

17. Haroon NN, Szabo E, Raboud JM, Mcdonald-Blumer H, Fung $L$, Josse RG, et al. Alterations of bone mineral density, bone microarchitecture and strength in patients with ankylosing spondylitis: a cross-sectional study using high-resolution peripheral quantitative computerized tomography and finite element analysis. Arthritis Res Ther. 2015;17:377. https://doi. org/10.1186/s13075-015-0873-1

18. Briot K, Roux C. Inflammation, bone loss and fracture risk in spondyloarthritis. RMD Open. 2015;1(1):e000052. https:// doi.org/10.1136/rmdopen-2015-000052

19. Sarikaya S, Basaran A, Tekin Y, Ozdolap S, Ortancil O. Is osteoporosis generalized or localized to central skeleton in ankylosing spondylitis? J Clin Rheumatol. 2007;13(1):20-4. https://doi.org/10.1097/01.rhu.0000255688.83037.4220
20. El Maghraoui A. Osteoporosis and ankylosing spondylitis Joint Bone Spine. 2004;71(4):291-5. https://doi.org/10.1016/j. jbspin.2003.06.002

21. Başkan BM, Doğan YP, Sivas F, Bodur H, Ozoran K. The relation between osteoporosis and vitamin D levels and disease activity in ankylosing spondylitis. Rheumatol Int. 2010;30(3):375-81. https://doi.org/10.1007/s00296-009-0975-7

22. Baek HJ, Kang SW, Lee YJ, Shin KC, Lee EB, Yoo CD, et al. Osteopenia in men with mild and severe ankylosing spondylitis. Rheumatol Int. 2005;26(1):30-4. https://doi.org/10.1007/ s00296-004-0516-3

23. Will R, Palmer R, Bhalla AK, Ring F, Calin A. Bone loss as well as bone formation is a feature of progressive ankylosing spondylitis. Br J Rheumatol. 1990;29(6):498-9. https://doi. org/10.1093/rheumatology/29.6.498-b

24. Devogelaer JP, Maldague B, Malghem J, Deuxchaisnes CN. Appendicular and vertebral bone mass in ankylosing spondylitis. A comparison of plain radiographs with single- and dual-photon absorptiometry and with quantitative computed tomography. Arthritis Rheum. 1992;35(9):1062-7. https://doi.org/10.1002/ art.1780350911

25. Ulu MA, Çevik R, Dilek B. Comparison of PA spine, lateral spine, and femoral BMD measurements to determine bone loss in ankylosing spondylitis. Rheumatol Int. 2013;33(7):1705-11. https://doi.org/10.1007/s00296-012-2632-9 